\begin{tabular}{l|l|l|l}
$\begin{array}{l}\text { Case Reports in } \\
\text { Demiliatology }\end{array}$ & $\begin{array}{l}\text { Case Rep Dermatol 2011;3:60-63 } \\
\text { DOI: 10.1159/000324344 }\end{array}$ & $\begin{array}{l}\text { Published online: } \\
\text { March 7, 2011 }\end{array}$ & $\begin{array}{l}\text { O 2011 S. Karger AG, Basel } \\
\text { ISSN 1662-6567 } \\
\text { www.karger.com/cde }\end{array}$ \\
\hline
\end{tabular}

\title{
Anti-Tumor Necrosis Factor-a Therapy in the Management of Psoriasis and B-Chronic Lymphocytic Leukemia
}

\author{
Anna Balato Serena Lembo Teresa Cirillo \\ Matteo Megna Annunziata Raimondo Luisa Di Costanzo \\ Department of Dermatology, University of Naples Federico II, Naples, Italy
}

\section{Key Words}

Anti-TNF-a drugs - B-chronic lymphocytic leukemia - Psoriasis - Tumor necrosis factor-a

\begin{abstract}
Psoriasis is a chronic immunologically-based inflammatory skin disease. B-chronic lymphocytic leukemia (B-CLL) is a form of leukemia characterized by the slow and progressive accumulation of monoclonal $C D 5+B$ lymphocytes in peripheral blood, bone marrow, lymph nodes and other organs. A T-helper 1 cytokine-mediated pathway is involved in these disorders in which tumor necrosis factor-a (TNF-a) plays a central role. TNF- $a$ is involved in physiological phenomena, such as host defense, inflammation and cell differentiation, and in many pathological conditions, such as fever and some malignant neoplasms. TNF-a involvement in psoriasis has been well validated by the clinical success of anti-TNF-a therapy. TNF-a has been well studied in the pathogenesis of $\mathrm{B}-\mathrm{CLL}$, suggesting it as a target in B-CLL therapy. We present the case of a patient suffering from plaque psoriasis and B-CLL. Since TNF-a is reported as a common link between psoriasis and $\mathrm{B}-\mathrm{CLL}$, the patient was treated with etanercept followed by infliximab, two anti-TNF-a drugs. During 3 years of therapy, the patient did not show significant modifications of lymphocyte levels, indicating no progression of B-CLL. We report this case to highlight the possibility to administer anti-TNF-a treatment in psoriatic patients affected by concomitant B-CLL.
\end{abstract}

\section{Introduction}

Psoriasis is a chronic immunologically-based inflammatory skin disease which affects approximately $2 \%$ of the general population $[1,2]$. The presence of an unknown antigen causes the generation of effector $\mathrm{T}$ cells that infiltrate the skin and initiate a pathogenetic process by producing different types of cytokines. Tumor necrosis factor- $\alpha$ (TNF- $\alpha$ ) is 
considered the most important cytokine involved in the pathogenesis of psoriasis $[3,4]$. Indeed, TNF- $\alpha$ plays an important physiological role in host defense, inflammation and cell differentiation, and a pathological role in many conditions such as fever, rheumatoid arthritis and some malignant neoplasms, e.g. B-chronic lymphocytic leukemia (B-CLL) [5].

B-CLL is the most common form of leukemia in the Western world, characterized by the slow and progressive accumulation of monoclonal CD5+ B lymphocytes in peripheral blood, bone marrow, lymph nodes and other organs [6]. B-CLL is the first example of an indolent cancer characterized by abnormally low apoptosis rather than increased mitosis [7]. Although multiple apoptosis inhibiting factors other than TNF- $\alpha$ have been identified in B-CLL, several data indicate that TNF- $\alpha$ is a central mediator in apoptosis resistance of malignant lymphocytes in B-CLL [8].

\section{Case Report}

A 41-year-old White woman, suffering from plaque psoriasis since she was 23 years old, was referred to our outpatient clinic. She was not affected by psoriatic arthropathy and was known to be in good health with no other illnesses, no history of major surgical procedures and was receiving no concomitant medications. The psoriasis involved the scalp and the palms (fig. 1a). In the past, topical corticosteroids and salicylic acid were applied with partial and temporary improvement. She was administered two 8-month cycles of cyclosporine treatment with moderate results in 2005 and 2006. In 2007 , she started phototherapy with ultraviolet B narrowband; she did not experience good results because of a scarce compliance to this kind of treatment. In order to start a new therapy based on biologic drugs, all routine laboratory tests (serum chemistry, hematology, and urinalysis) were performed. The results were normal except for a moderate lymphocytosis (63\%, normal range 20-45\%; $6.32 \times 10^{3} / \mu \mathrm{l}$, normal range $1.2-3.5 \times 10^{3} / \mu \mathrm{l}$ ) with a normal white blood cell count. Afterwards, laboratory tests were repeated and moderate lymphocytosis was present again; according to this evidence, a hematologic counseling was required, and the diagnosis of B-CLL was made. Since TNF- $\alpha$ is reported as a common link between psoriasis and B-CLL, two cycles of etanercept were administered (1 cycle $=12$ weeks $)$ from January to June 2008. Lymphocyte levels remained stable $\left(61 \% ; 6.1 \times 10^{3} / \mu \mathrm{l}\right)$, indicating no progression of the leukemia, but after 24 weeks of treatment, the patient did not achieve psoriasis area and severity index (PASI) 50 (a 50\% reduction in PASI score). Therefore, in December 2008 , she was started on a course of treatment with infliximab ( $5 \mathrm{mg} / \mathrm{kg}$ intravenous). After the $3 \mathrm{rd}$ infusion of infliximab, a significant improvement of clinical manifestations was observed (fig. 1b). PASI and body surface area decreased from 12.4 to 5.5 and from 18.8 to $9.0 \%$, respectively. Furthermore, lymphocyte levels remained stable $\left(60 \% ; 6.22 \times 10^{3} / \mu \mathrm{l}\right)$. After 18 months of infliximab treatment, lymphocyte levels remained stable and psoriatic manifestations were under control.

\section{Discussion}

Here, we have described the case of a patient suffering from plaque psoriasis and BCLL. The patient had suffered from psoriasis for 18 years and, like many other subjects with moderate-to-severe psoriasis, had received a series of different treatments (topical and systemic) in an attempt to control symptoms. Laboratory tests showed a moderate lymphocytosis so that a hematologic counseling was required and a diagnosis of B-CLL was made.

A T-helper 1 cytokine-mediated pathway is involved in these disorders in which TNF$\alpha$ plays a central role [9]. TNF- $\alpha$ involvement in psoriasis has been well validated by the clinical success of anti-TNF- $\alpha$ therapy [1]. On the other hand, TNF- $\alpha$ is constitutively produced by B-CLL cells, and it may act as an autocrine factor for their growth and 
survival [10]. Moreover, in B-CLL patients, TNF- $\alpha$ serum levels and soluble TNF- $\alpha$ receptor (sTNFR) levels are increased, and a correlation with disease progression has been demonstrated, associated with an adverse prognosis; it has been hypothesized that high levels of TNF- $\alpha$ and sTNFR can predict outcome in lymphoma patients [11]. Ferraioli et al. [12] confirmed the relationship between TNF- $\alpha$ plasma levels and the severity of BCLL, suggesting that they should be monitored together with other disease markers.

The observations described above prompted a course of treatment with anti-TNF- $\alpha$ therapy. The first drug chosen was etanercept, a dimeric fusion protein consisting of the extracellular ligand-binding portions of two soluble TNF-a receptors fused to a Fc fragment of an immunoglobulin G1 molecule. Two cycles of etanercept were administered ( $50 \mathrm{mg}$ twice a week for 12 weeks followed by $50 \mathrm{mg}$ every week until 24 weeks) with poor effects on psoriatic disease and no B-CLL progression. Therefore, the patient was started on a course of treatment with infliximab ( $5 \mathrm{mg} / \mathrm{kg}$ intravenous). Infliximab is a chimeric murine/human immunoglobulin G1 monoclonal antibody that binds specifically to human TNF- $\alpha$. In our case, psoriatic lesions improved and B-CLL showed a lack of progression during infliximab therapy. During 3 years of anti-TNF- $\alpha$ therapy, the patient did not show significant modifications of lymphocyte levels.

\section{Conclusion}

On the basis of this evidence, TNF- $\alpha$ could represent a therapeutic target in patients affected by both psoriasis and B-CLL; specific inhibition of TNF- $\alpha$, either with dimeric fusion protein etanercept or the monoclonal antibody infliximab, could potentially result in the control of proliferation of the leukemic clone. We report this case to highlight the possibility to administer anti TNF- $\alpha$ treatment in psoriatic patients affected by concomitant B-CLL.

\section{Disclosure Statement}

The authors have no conflicts of interest. 


\begin{tabular}{l|l|l|l}
$\begin{array}{c}\text { Case Reports in } \\
\text { Demillatology }\end{array}$ & $\begin{array}{l}\text { Case Rep Dermatol 2011;3:60-63 } \\
\text { DOI: } 10.1159 / 000324344\end{array}$ & $\begin{array}{l}\text { Published online: } \\
\text { March 7, 2011 }\end{array}$ & $\begin{array}{l}\text { O 2011 S. Karger AG, Basel } \\
\text { ISSN 1662-6567 } \\
\text { www.karger.com/cde }\end{array}$ \\
\hline
\end{tabular}
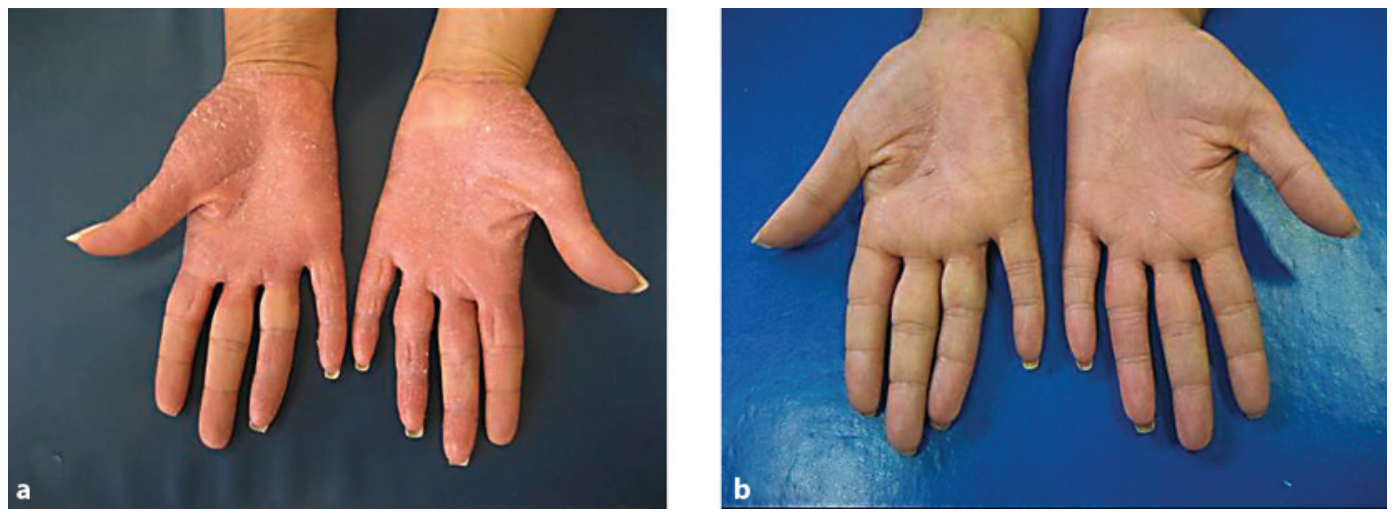

Fig. 1. Clinical features before starting therapy (a) and after the 3rd infusion of infliximab (b).

\section{References}

1 Nestle FO, Kaplan DH, Barker J: Psoriasis. N Engl J Med 2009;361:496-509.

-2 Sabat R, Philipp S, Hoflich C, Kreutzer S, Wallace E, Asadullah K, Volk HD, Sterry W, Wolk K: Immunopathogenesis of psoriasis. Exp Dermatol 2007;16:779-798.

-3 Caldarola G, De Simone C, Carbone A, Tulli A, Amelio P, Feliciani C: TNFalpha and its receptors in psoriatic skin, before and after treatment with etanercept. Int J Immunopathol Pharmacol 2009;22:961-966.

4 Orlinick JR, Chao MV: TNF-related ligands and their receptors. Cell Signal 1998;10:543-551.

5 Gruss HJ, Dower SK: Tumor necrosis factor ligand superfamily: involvement in the pathology of malignant lymphomas. Blood 1995;85:3378-3404.

6 Rozman C, Montserrat E: Chronic lymphocytic leukemia. N Engl J Med 1995;333:1052-1057.

7 Kolb JP, Kern C, Quiney C, Roman V, Billard C: Re-establishment of a normal apoptotic process as a therapeutic approach in B-CLL. Curr Drug Targets Cardiovasc Haematol Disord 2003;3:261-286.

-8 Jetovic-Stoimenov T, Kocic G, Pavlovic D, Macukanovic-Golubovic L, Marjanovic G, Djordjevic V, Tosic N, Pavlovic S: Polymorphisms of tumor-necrosis factor-alpha -308 and lymphotoxin-alpha +250 : possible modulation of susceptibility to apoptosis in chronic lymphocytic leukemia and non-Hodgkin lymphoma mononuclear cells. Leuk Lymphoma 2008;49:2163-2169.

-9 Gallego A, Vargas JA, Castejon R, Citores MJ, Romero Y, Millan I, Durantez A: Production of intracellular IL2, TNFa and IFN $\gamma$ by T cells in B-CLL. Cytometry B Clin Cytom 2003;56:23-29.

10 Rosati E, Sabatini R, Tabilio A, Di Ianni M, Bartoli A, Marconi P: B chronic lymphocytic leukemia cells exert an in vitro cytotoxicity mediated by TNFa. Leuk Res 2005;29:829-839.

11 Waage A, Liabakk N, Lien E, Lamvik J, Espevik T: p55 and p75 tumor necrosis factor receptors in patients with chronic lymphocytic leukemia. Blood 1992;80:2577-2583.

-12 Ferraioli A, Keating MJ, Taghi M, Gilles FJ, Dey A, Estrov Z, Koller CA, Kurzrock R, Thomas DA, Faderl S, Lerner S, O'Brien S, Albitar M: The clinical significance of tumor necrosis factor-alpha plasma level in patients having chronic lymphocytic leukemia. Blood 2002;100:1215-1219. 